\title{
Determining the adsorption and desorption behavior of thiabendazole fungicide for five different agricultural soils
}

\author{
Taghazal Zahra*, Khuram Shahzad Ahmad, Irum Shaheen, Sundus Azhar and Shaan Bibi Jaffri \\ Department of Environmental Sciencses, Fatima Jinnah Women University, Rawalpindi
}

\begin{abstract}
Thiabendazole 2-(4'-thiazolyl)benzimidazole (TBZ) is a Benzimidazole fungicide. In the present study adsorption and desorption of TBZ was investigated through batch equilibrium method involving UV-Visible spectrophotometer and High-performance liquid chromatography. Linear and Freundlich coefficients and kinetics of TBZ was studied in different agricultural soils of Pakistan. $9.8 \mu \mathrm{gml}^{-1}$ and $12.09 \mu \mathrm{gml}^{-1}$ were highest values of $K_{d}$ ads and $K_{d \text { des }}$ respectively. $K_{f}$ ads values ranged from 6.6 to $8 \mu \mathrm{gml}^{-1}$ whereas values of $K_{f \text { des }}$ followed the range of $1.5 \mu \mathrm{gml}^{-1}$ to $9.8 \mu \mathrm{gml}^{-1}$. Most of the samples depict negative hysteresis as their $1 / n_{\text {des }}$ was more than $1 / n_{\text {ads. }}$ Gibbs or free energy change $(\Delta G)$ and hysteresis vividly proved physical and reversible adsorption process. The values of $K_{\text {om }}$ and $K_{o c}$ were indicated medium mobility group of TBZ in selected soils. However all kinetic values varied significantly from sample to sample depending on their physicochemical parameters.
\end{abstract}

Keywords: Thiabendazole (TBZ), linear isothermal model, Freundlich isothermal model, UV-Visible spectrophotometer

\section{Introduction}

Thiabendazole, 2-(4'-thiazolyl) (TBZ) is a Benzimidazole fungicide that interact with tubulin and especially $\beta$-tubulin. TBZ was first introduced as an anti helmintic agent. With the passage of time antifungal properties of TBZ were also reported. Later on it was discovered that TBZ has huge potential for regulating and controlling various fungus diseases. Moreover TBZ is systemic benzimidazole based fungicide which making it more efficient as a broad disease control agent. The antifungal spectrum of TBZ is broad however selective as well as some pathogens are resistant to it. It is practiced for monitoring and mitigating the diseases of fruits and other vegetable such as mold, blight, pear scab and stain, rots, etc (López et al., 2003 ; Séìde et al., 2016) Figure 1.

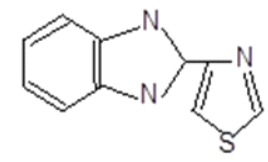

Figure 1: Structure of TBZ

Thiabendazole [2-(4thaizolyl)benzimidazole]

Adsorption desorption behavior of pesticide in various soils have been mentioned in a lot of researches in literature(Ahmad et al., 15; Doretto et al., 2014; Ahmad et al., 2014;Rauf et al., 2012; Shariff, 2012; Bansal, 2010; Shariff, 2009). Regulatory agencies need adsorption and soil mobility data before registering pesticides but such data are not usually adequate to precisely predict the fate and mobility of any specific chemical in environment. Detection of compounds such as hydrophobic pesticides (considered as immobile based on their partition coefficients) in remote ecosystems and ground water bodies is indicative of an incomplete understanding of adsorption and desorption processes of pesticide in natural environments (Alamdar et al., 2014) however to overcome this knowledge gap, besides continued fundamental research, there is need of comprehensively synthesize existing research findings related to the sorption of a pesticide (Damalas et al., 2011).

Current investigation is based on sorptive behavior of TBZ in terms of concentration dependence. Soils under investigation were sampled from geographically distinct regions of Pakistan. The correlative impact of various physicochemical parameters i.e. organic content, $\mathrm{pH}$ and clay content has also been investigated. Therefore, present work is environment based emphasizing on the pedospheric region of Pakistani environment.

\section{Materials and Methods}

\section{Apparatus and chemicals required}

Solvents and chemicals required for the current study are analytically grade acetone and methanol $99.9 \%$ pure, Sodium Chloride and Calcium Chloride anhydrous powder and analytical grade Thiabendazole (Fluka).

*Email: taghazalzahra123@gmail.com 


\section{Soil sampling, preparation and analysis}

Five agricultural regions from different provinces of Pakistan were selected for observing differences in their physicochemical properties. The soil samples were air dried for about 24 hours. The soils were prepared and homogenized using a mortar, pestle and $2 \mathrm{~mm}$ sieve. Prepared soil samples were used for estimation of physiochemical properties (Table 2) following Standard Test Method (STM) (OECD, 2005; Shariff, 2012).

\section{Adsorption and desorption experiments}

Adsorption and desorption of TBZ were carried out by using batch equilibrium method. (OECD, 2005; Chakrabortyand Sun, 2014) All experiments were done at laboratory isothermal and ambient conditions $24^{\circ} \mathrm{C}$ to $26^{\circ} \mathrm{C}$.Duplicate air-dried soil samples were equilibrated with $8(0,0.25,0.5,0.75,1.0,2.5,5.0$ and $7.5 \mathrm{ppm})$ different concentrations for TBZ, while Sorbent solution ratio was kept at 1:20 in order to acquire reliable and consistent results from the experiments. All samples along with duplicates plus blanks (no pesticide) and control (no soil) were thermostated and agitated in orbital Shaker at room temperature for appropriate time duration (24 hours usually) and at 90rpm velocity to attained equilibrium The valves were centrifuged for $20 \mathrm{~min}$. at $3500 \mathrm{rpm}$. Three $\mathrm{ml}$ of the clear supernatant was removed, filtered through $0.2 \mu \mathrm{m}$ nylon filters and analyzed for the pesticide concentration. Using UV-visible spectrophotometer (Model: BMS-1602) and HPLC (Model: LC-20 AT UFLC by schinal 24, Japan), the concentration of TBZ in solution was analyzed for compound identification and quantification.

At UV-visible spectrophotometer, the solutions were run at detection wavelength of $288 \mathrm{~nm}$ by taking water as the reference standard. The HPLC was equipped with a reverse phase column and the operating conditions were selected as: the mobile phase was water and methanol (30:70) with a flow rate of $0.8 \mathrm{~mL} / \mathrm{min}$, and the column oven temperature was $30^{\circ} \mathrm{C}$. Under the above conditions, the retention time for TBZ was 6 min. Desorption processes were done as each valve was placed in a thermostated shaker. Once the adsorption was done, reminder of the supernatant discarded and immediately replaced by $9 \mathrm{ml}$ freshly prepared $0.1 \mathrm{M} \mathrm{CaCl}_{2}$ solution. The samples were again shaken, centrifuged and analyzed at same condition as for adsorption, for the kinetic study for each pesticide.

\section{Data analysis}

The distribution coefficient $\left(\mathrm{K}_{\mathrm{d}}\right)$ of both adsorption and desorption was calculated by taking the ratio of $\mathrm{C}_{s}$ to $\mathrm{C}_{e}$

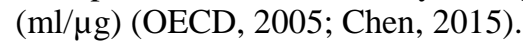

$$
\left.\mathrm{K}_{\mathrm{d}}=\mathrm{C}_{\mathrm{s}}(\text { ads, des } \mu \mathrm{g} / \mathrm{g}) / \mathrm{C}_{\mathrm{e}} \text { (find ppm, } \mu \mathrm{g} / \mathrm{ml}\right) \ldots 2
$$

$\mathrm{C}_{\mathrm{s}}$ is the amount of the pesticide adsorbed on the soilwhile $\mathrm{C}_{\mathrm{e}}$ which is equilibrium concentration of pesticide in solution. Adsorption isotherm parameters were calculated using the linear form of Freundlich equation (OECD, 2005; Chen, 2015).

$$
\log C_{s}=\log K_{f}+1 / n \log C_{e} \ldots 3
$$

Here $\mathrm{K}_{\mathrm{f}}=$ Freundlich adsorption coefficient, $1 / \mathrm{n}=$ Slope of Freundlich adsorption isotherm, $\mathrm{n}$ is a linearity factor, it is also known as adsorption intensity, $\log \mathrm{K}_{\mathrm{f}}$ is the intercept of the straight line resulting from the plot of $\log \mathrm{C}_{\mathrm{s}}$ versus $\log \mathrm{C}_{\mathrm{e}}$ while $\mathrm{C}_{\mathrm{s}}$ and $\mathrm{C}_{\mathrm{e}}$ are defined previously.

The standard Gibbs or free energy change of adsorption $(\Delta \mathrm{G})$ from the Freundlich isotherm can be calculated using the following relation (Shariff, 2012; Ahmad et al., 2014).

$$
\Delta \mathrm{G}=-\mathrm{RTLnK}_{\mathrm{om}}
$$

Hysteresis coefficient Hysteresis coefficients $(\mathrm{H})$ can be determined by using the following equation (Shariff, 2012; Ahmad et al., 2014).

$$
\mathrm{H}=\mathrm{n}_{\mathrm{a}} \mathrm{n}_{\mathrm{Ags}} 5
$$

Where $\mathrm{n}_{\mathrm{a}}$ and $\mathrm{n}_{\text {des }}$ ratio for Ferundlich adsorption and desorption constants, respectively (Chakrabortyand Sun, 2014). The linear or distribution coefficient $\left(K_{d}\right)$ is related to soil organic carbon (OC) and soil organic matter (OM) by the following equations (Shariff, 2012; Ahmad et al., 2014).

$$
\begin{gathered}
\% \mathrm{OC}=\% \mathrm{OM} / 1.724 \ldots 6 \\
\mathrm{~K}_{\mathrm{OM}}=100 \times \mathrm{K}_{\mathrm{d}} /(\% \mathrm{OC}) \ldots 7 \\
\mathrm{~K}_{\mathrm{OC}}=100 \mathrm{~K}_{\mathrm{d}} /(\% \mathrm{OC}) \ldots 8 \\
\text { T. Nitrogen }=\% \mathrm{OM}-0.05 \ldots 9
\end{gathered}
$$

\section{Results and Discussion}

Linear and Freundlich isotherms were studied in present research. Sorption kinetics of Freundlich sorption model as well as linear equilibrium model was investigated using isotherms and data analysis given in methodology (Figure 2, 3, 4, 5 and Table 01)

$\mathrm{K}_{\mathrm{d} \text { ads }}$ for all studied soil samples were ranged from $6.99 \mathrm{ugml}^{-1}$ to $9.8 \mathrm{\mu gml}^{-1}$ while $\mathrm{K}_{\mathrm{d} \text { des }}$ was varied from $5.86 \mu \mathrm{gml}^{-1}$ to $12.09 \mu \mathrm{gml}^{-1}$. Similarly $\mathrm{K}_{\mathrm{f} \text { ads }}$ ranged from 6.6 to 8 while values of $K_{f}$ des are ranging between 1.5 and 9.8 . $\mathrm{K}_{\text {om }}$ followed the range from 351.6 to 460 implying high to medium mobility of TBZ. For TBZ $\mathrm{K}_{\mathrm{oc}}$ ranged from 606.145 to 792.87 signifying that TBZ has little to no 
leaching potential which is depending on soil type (Bansal, 2010; Ahmad et al., 2014).

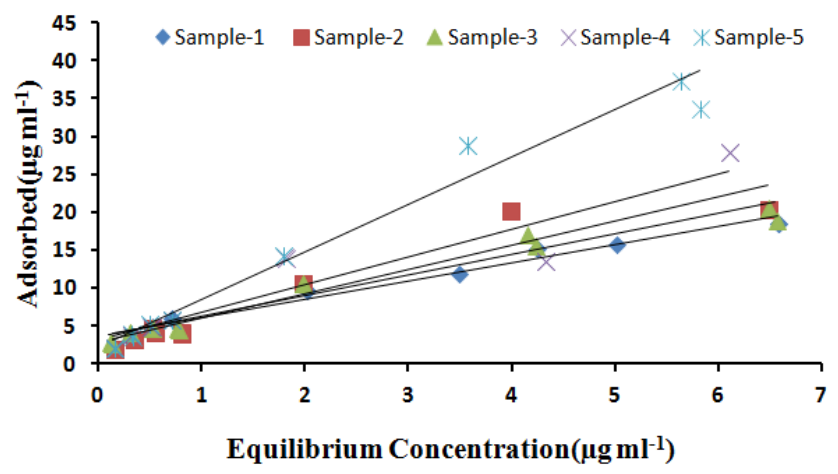

Figure 2: Linear isotherms for TBZ adsorption in selected soils

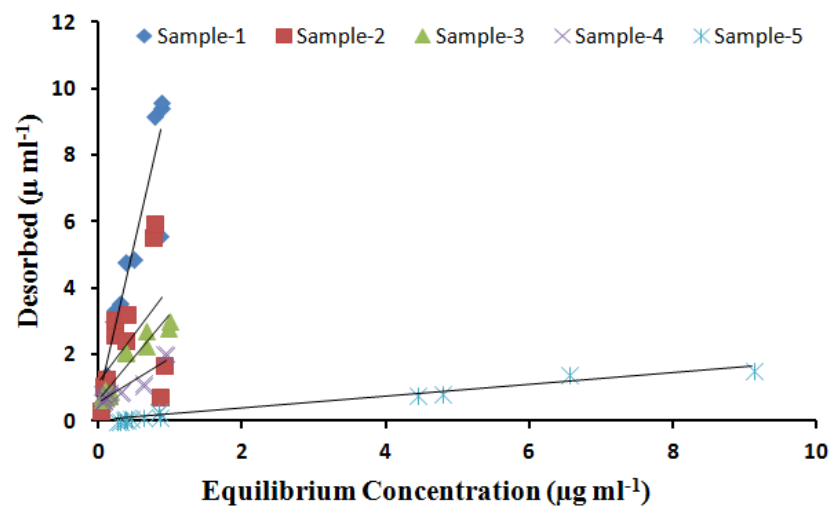

Figure 3: Linear isotherms for TBZ desorption in selected soils

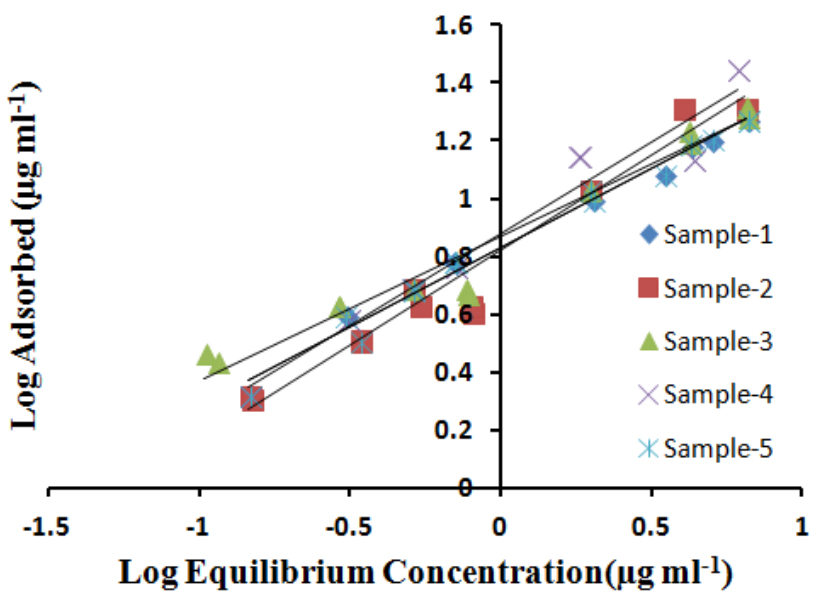

Figure 4: Freundlich isotherms for TBZadsorption in selected soils

The values of $\Delta \mathrm{G}$ are in range from -15.1 to $14.0 \mathrm{kjmol}^{-1}$. The negative value of $\Delta \mathrm{G}$ indicates that the interaction of TBZ on the selected soils is spontaneous and exothermic (Shariff, 2012) Table 2 also demonstrates the values of adsorption intensity $\mathrm{n}_{\mathrm{ads}}$ which are in range from 0.5 to 0.8 . In present study desorption hysteresis coefficient, $\mathrm{H}$, in all five soils varied between 0.66 to 2.03 , which was indicating that hysteresis is absent because value of $\mathrm{H}$ close to 1 means that desorption process as quickly as sorption does (Doretto et al., 2014).

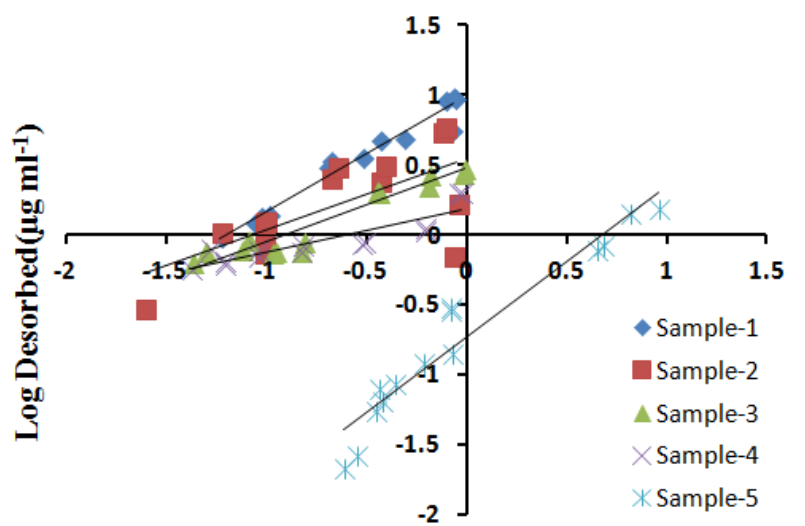

$\log$ Equilibrium Concentration $\left(\mu \mathrm{g} \mathrm{ml}^{-1}\right)$

Figure 5: Freundlich isotherms for TBZdesorption in selected soils

In present research Linear and Freundlich models were found to be best fitted models for adsorption and desorption studies of TBZ because of its higher values of $\mathrm{R}$ square ( 0.86 to 0.99 for adsorption and 0.82 to 0.97 for desorption) with lower S.E. (0.03to 0.36 foradsorption and 0.048 to .62 for desorption) (Rauf et al., 2012; Chen, 2015).

\section{Effect of Soil physiochemical properties on sorption kinetics of TBZ}

Table 1 represents linear and Freundlich kinetics $\left(\mathrm{K}_{\mathrm{d}}\right.$, $\mathrm{K}_{\mathrm{f}}, \mathrm{K}_{\mathrm{om}}, \mathrm{K}_{\mathrm{oc}}$, Hysteresis coefficient and thermodynamic parameters for TBZ. All these parameters were than evaluated on the bases of the physico-chemical characteristics of each soil as presented in table 2, figure 6 . With the increasing SOM, values of adsorption coefficients increases while decreasing SOM was found to be responsible for increasing desorption characteristics of pesticide (Boivin et al 2005; Bansal, 2010)as shown in figure 6. Thus SOM is positively correlated with adsorption kinetics as proved by the fact that Soil sample-3 has highest values of $\mathrm{K}_{\mathrm{d} \text { ads }}$ and $\mathrm{K}_{\mathrm{fads}}$ because of highest values of SOM. Presences of total nitrogen and TOC would increase soil organic matter, as a result adsorption of TBZ increase and values of $\mathrm{K}_{\mathrm{d}}$ and $\mathrm{K}_{\mathrm{f}}$ would be higher. Therefore adsorption isotherm parameter has positive correlation with organic carbon and nitrogen of soil as revealed by data in table 1 and 2. 
Sorption studies of TBZ

Table 1: Quantitative determination of TBZ adsorptive interactions with selected soils

\begin{tabular}{|c|c|c|c|c|c|c|}
\hline Models & Parameters & Sample-1 & Sample- 2 & Sample-3 & Sample-4 & Sample-5 \\
\hline \multirow{8}{*}{$\begin{array}{ll}\text { Linear } & \text { adsorption/ } \\
\text { desorption } & \text { models }\end{array}$} & $\mathbf{k}_{\mathbf{d}}$ ads $\left(\mu \mathrm{gml}^{-1}\right)$ & 7.08 & 6.99 & 9.8 & 8.6 & 8.5 \\
\hline & $\mathbf{K}_{\mathbf{d}} \operatorname{des}\left(\mu \mathrm{gml}^{-1}\right)$ & 9.7 & 12.09 & 5.86 & 6.1 & 5.9 \\
\hline & $\mathbf{r}^{2}$ ads & 0.96 & .98 & .96 & .88 & .99 \\
\hline & S ads & 0.19 & .116 & .095 & .36 & .03 \\
\hline & $\mathbf{r}^{2}$ des & 0.94 & .91 & .84 & .82 & .97 \\
\hline & $\mathrm{S}$ des & 0.58 & .62 & .23 & .125 & .49 \\
\hline & $\mathbf{K}_{\mathbf{o c}}$ & 670.86 & 606.145 & 792.87 & 716.24 & 792.87 \\
\hline & $\mathbf{K}_{\mathrm{om}}$ & 389.135 & 351.6 & 459.9 & 415.455 & 460 \\
\hline \multirow{11}{*}{$\begin{array}{l}\text { Gibbs energy change } \\
\text { Frendlich adsorption/ } \\
\text { desorption model }\end{array}$} & $\Delta \mathbf{G}$ & -14.66 & -15.1 & -14.0 & -14.6 & -15.1 \\
\hline & $\mathbf{K}_{\mathrm{f}} \operatorname{ads}\left(\mu \mathbf{g m}^{-1}\right)$ & 6.76 & 6.6 & 8 & 7.6 & 7.02 \\
\hline & $K_{\mathrm{f}} \operatorname{des}\left(\mu \mathrm{gml}^{-1}\right)$ & 5.67 & 9.8 & 1.5 & 2.9 & 3.52 \\
\hline & $\mathbf{r}^{2}$ ads & .99 & 0.97 & 0.96 & 0.96 & 0.99 \\
\hline & S ads & 0.037 & 0.058 & 0.067 & 0.082 & 0.04 \\
\hline & $\mathbf{r}^{2}$ des & 0.96 & 0.94 & 0.97 & 0.86 & 0.92 \\
\hline & $\mathrm{S}$ des & 0.08 & .068 & .048 & .05 & .16 \\
\hline & $1 / n$ ads & 1.03 & 1.52 & 2.01 & 3.2 & 1.2 \\
\hline & 1/n des & 1.209 & 1.96 & 1.89 & 1.6 & 1.158 \\
\hline & $\mathbf{n}_{\mathbf{a}}$ & .66 & .8 & .5 & .56 & .63 \\
\hline & $\mathbf{n}_{\text {des }}$ & .53 & .312 & .86 & .827 & .51 \\
\hline Hysteresis coefficient & $\mathbf{H}$ & 0.66 & 0.93 & 2.03 & 1.29 & 0.94 \\
\hline
\end{tabular}

Table 2: Physicochemical characteristics of selected soils

\begin{tabular}{lllllllll}
\hline \multirow{2}{*}{ Sample } & \multirow{2}{*}{ Area } & \multicolumn{4}{c}{ Physiochemical Property } \\
\cline { 3 - 8 } & & pH & OM & Clay & CEC & T.N & TOC & Texture \\
\hline Sample-1 & Buner & 7.49 & 1.82 & 22 & 6.3 & 1.056 & 0.091 & Sandy clay loam \\
Sample-2 & Abbottbad & 7.5 & 1.52 & 20 & 6.1 & 0.076 & 0.882 & Sandy clay loam \\
Sample-3 & Poonch & 6.84 & 2.8 & 55 & 8.2 & 0.14 & 1.62 & Clay \\
Sample-4 & Mandi Bahaud Din & 6.96 & 2.07 & 36 & 7.7 & 0.103 & 1.203 & Sandy clay \\
Sampe-5 & Zhob Baluchistan & 7.42 & 2.01 & 30 & 7.3 & 0.100 & 1.166 & Sandy clay loam \\
\hline
\end{tabular}

$\mathrm{OM}=$ Organic Matter (\%), CEC (meq $100 \mathrm{~g}^{-1}$ )

Table 2 shows that sample-1 and sample-2 have comparatively lower values of CEC, sample-3 has highest value of CEC and last two samples in table 2 also exposed higher values as compared to sample- 1 and sample- 2 . When CEC values are compared with data in table 1 , it was revealed that CEC was responsible for enhancing adsorption parameters and depicted negative correlation with desorption parameters as shown in figure 6 . Adsorption and desorption characteristics were also investigated with respect to $\mathrm{pH}$ of soil samples represented in Figure 6. Soil sample-3, sample-4 and sample-5 have lower values of $\mathrm{pH}$ but depicted higher values of adsorption coefficients and lower values desorption coefficients. Therefore $\mathrm{pH}$ is negatively correlated with adsorption and positive correlated with desorption parameters ( Muszynski and Brodowska, 2014)

Clay content of selected soils ranged from $20 \%$ to55\% thus presenting significant diversity in clay content. As shown in figure 6 , sample- 3 has $55 \%$ clay content which is an important factor for encouraging adsorption of TBZ. Sample-2 and sample-1 have lower values of clay content which results in lower mobility and lower values of desorption parameters. This is because of the fact that Clay soil has more vacant sites or surfaces for a chemical to adsorb. While sandy soil has fewer pores or adsorption sites which result in minimum adsorption (Onojake and Osuji, 2012). Soil smaple-2 shows highest values for desorption as it has highest content for sand.Soil sample-3has highest clay content thereby have highest values of $\mathrm{K}_{\mathrm{d} \text { ads }}$ and $\mathrm{K}_{\mathrm{f} \text { ads }}$

\section{Effect of soil physiochemical properties on mobility and leaching of TBZ}

Effect of soil physiochemical properties on mobility and leaching of TBZ has been presented in figure $7 . \mathrm{K}_{\mathrm{oc}}$ has been used for calculating index of leachability of pesticide to groundwater and $\mathrm{K}_{\mathrm{om}}$ is used for quantifying pesticide's 
adsorption strength in soil because of robust correlation between $\mathrm{K}_{\mathrm{d}}$ and soil organic matter (Shariff, 2012; Dada, et al., 2012). Usually values of $\mathrm{K}_{\mathrm{oc}}$ and $\mathrm{K}_{\mathrm{om}}$ below 500 specify minimum or no adsorption at all of a pesticide to the soil indicate high probability of runoff or leaching. Pesticides have been categorized into three classes based on $\mathrm{K}_{\mathrm{oc}}$ by Shan et. al i.e. very high mobility group having $\mathrm{k}_{\mathrm{oc}}$ values less than 50, high to medium mobility group having $\mathrm{K}_{\mathrm{oc}}$ values 150 to 500 and low mobility group having $K_{o c}$ values more than 500 (Ahmad et al., 2014). Values of these two parameters strongly dependents on nature and properties of soil (Figure 7).
SOM reduce mobility of pesticides consequently higher will be $\mathrm{K}_{\mathrm{oc}}$ and $\mathrm{K}_{\mathrm{om}}$ values as shown in Sample-3 in Figure 7 , sample-3 has highest clay content, SOM but lowest values of sand content thus Sample- 3 have highest values of $\mathrm{K}_{\mathrm{om}}$ and $\mathrm{K}_{\mathrm{oc}}$. On other hand sample-2 has highest sand content and lowest clay content and SOM which results in comparatively higher mobility and significant leaching potential of TBZ.

\section{Conclusion}

UV spectrophotometer and HPLC techniques revealed the physical adsorption of TBZ took place on selected soils.

\section{Sorption Coefficients and Soil Physiochemical properties}

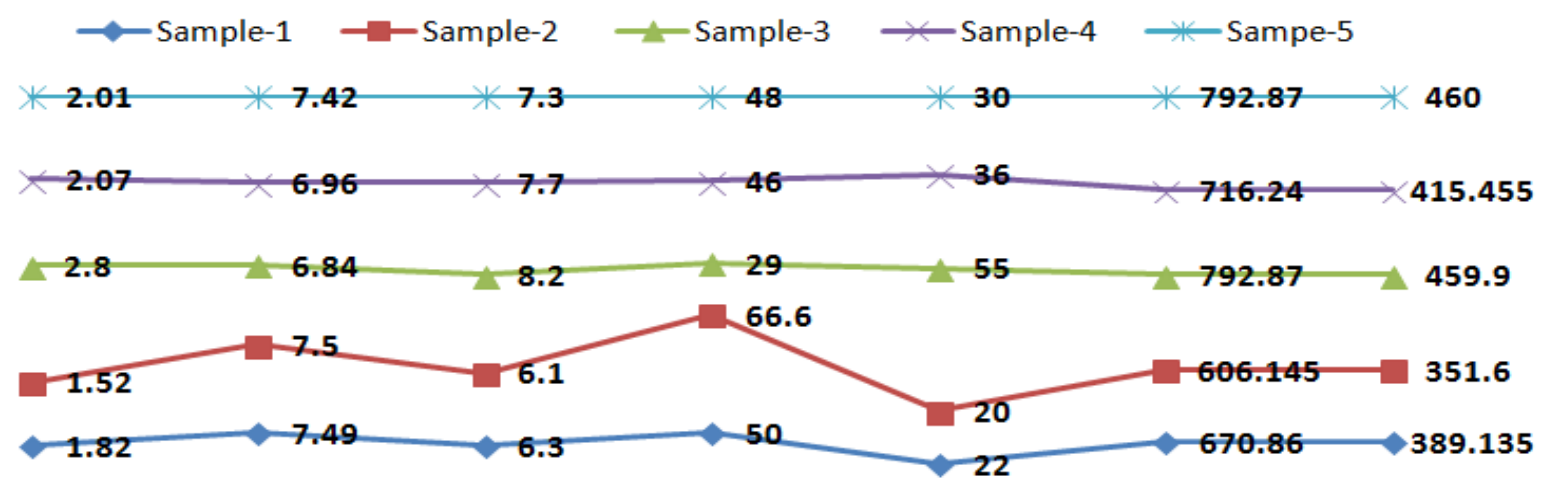
som
pH
CEC
sand
Clay
Koc
Kom

Figure 6: Soil physicochemical characteristics and sorption behavior

Koc, Kom and Soil Physiochemical Properties

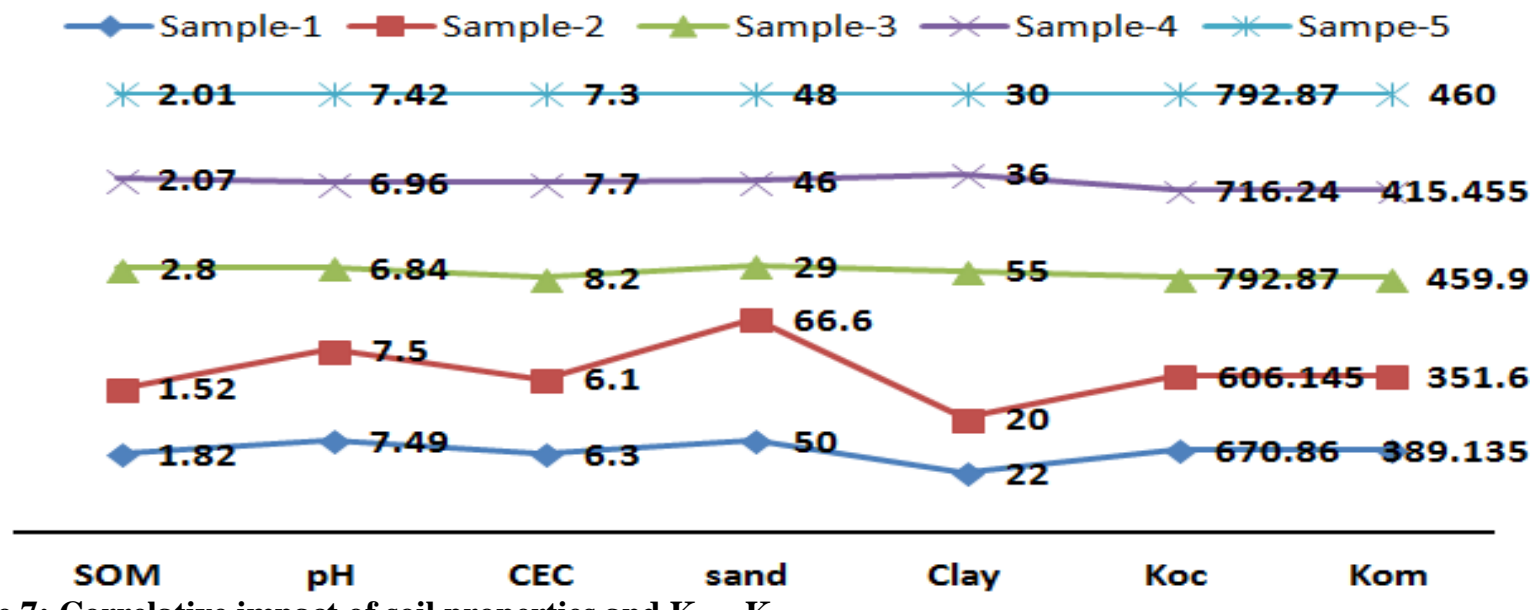

Figure 7: Correlative impact of soil properties and $K_{o m}, K_{o c}$

As shown figure $7, \mathrm{pH}$ and sand content is negatively correlated with $\mathrm{K}_{\mathrm{oc}}$ and $\mathrm{K}_{\mathrm{om}}$. Higher sand content facilities mobility and leaching of pesticide thereby lower would be $\mathrm{K}_{\mathrm{oc}}$ and $\mathrm{K}_{\mathrm{om}}$ values (Doretto et al., 2014). Clay content and
When Linear and Freundlich models were studied, TBZ in all the soils were found to be good fitted to the Linear and Freundlich sorption equation. $\mathrm{K}_{\mathrm{f}}$ and $\mathrm{K}_{\mathrm{d}}$ were used as approximate indicator of sorption capacity in present 
research. Values of hysteresis coefficient $(\mathrm{H})$ were signifying the absences of hysteresis.Sample- 3 has highest adsorption potential for TBZ because of its significant SOM and clay content therefore values of $\mathrm{K}_{\mathrm{d} \text { ads }}$ and $\mathrm{K}_{\mathrm{f}}$ ads were comparatively higher for sample- 3 and then for sample 4 . While lower values of $\mathrm{K}_{\mathrm{d} \text { ads }}$ and $\mathrm{K}_{\mathrm{f}}$ ads were found for sample-2, sample-1and sample-5 respectively. Values of $K_{d}$ des and $K_{f \text { des }}$ were relatively higher for sample-2, sample-1 therefore these two samples has min potential for TBZ to adsorbed.

Results of $\mathrm{K}_{\mathrm{om}}$ indicated high mobility of TBZ for Sample-1 and sampel-2 while medium mobility for rest of three samples was indicated by $\mathrm{K}_{\mathrm{om}}$. According to $\mathrm{K}_{\mathrm{oc}}$ little or no leaching potential was associated with TBZ for tested soils. Adsorption and desorption of TBZ was largely dependent on soil's characteristic. Organic matter, $\mathrm{pH}$, clay content, TOC and TN were found to be most important parameters while studying the sorption of TBZ.

\section{Acknowledgements}

The authors acknowledge faulty of Department of Environmental Sciences, Fatima Jinnah Women University Rawalpindi Pakistan.

\section{References}

Ahmad, K.S. and N. Rashid. 2015. Sorption-Desorption Behavior of Newly synthesized N-(1HBenzimidazole-2 ylmethyl) Acetamide (ABNZ) on Selected Soils and its Antifungal activity. Journal of the Chemical Society of Pakistan 37(4): 841-849.

Ahmad, K.S., N. Rashid, M.F. Nazar and S. Tazaiyen. 2014. Adsorption and Desorption Characteristic of Benzimidazole Based Fungicide Carbendazim in Pakistani Soils. Journal of the Chemical Society of Pakistan 34(3):35(3):1017-1024.

Alamdar, A., J.H. Syed, R.N. Malik, A. Katsoyiannis, J. Liu, J. Li and K.C. Jones. 2014. Organochlorine pesticides in surface soils from obsolete pesticide dumping ground in Hyderabad City, Pakistan: contamination levels and their potential for air-soil exchange. Science of the Total Environment 470: 733741.

Bansal, O.P. 2010. The Effects of composts on adsorption-desorption of three carbamate pesticides in different soils of Aligarh district. Journal of Applied Sciences and Environmental Management 14(4):155158.

Boivin, A., R. Cherrier and M. Schiavon. 2005. A comparison of five pesticides adsorption and desorption processes in thirteen contrasting field soils. Chemosphere 61(5): 668-676.
Chakraborty, A. and B. Sun. 2014. An adsorption isotherm equation for multi-types adsorption with thermodynamic correctness. Applied Thermal Engineering 72(2): 190-199.

Chen, X. 2015. Modeling of experimental adsorption isotherm data. Information 6(1): 14-22.

Rauf, N., S.S. Tahir, J.H. Kang and Y.S. Chang. 2012. Equilibrium, thermodynamics and kinetics studies for the removal of alpha and beta endosulfan by adsorption onto bentonite clay. Chemical engineering journal 192: 369-376.

Dada, A.O., A.P. Olalekan, A.M. Olatunya and O. Dada. 2012. Langmuir, Freundlich, Temkin and DubininRadushkevich isotherms studies of equilibrium sorption of $\mathrm{Zn} 2+$ unto phosphoric acid modified rice husk. IOSR Journal of Applied Chemistry 3(1): 38-45.

Damalas, C. A. and I.G. Eleftherohorinos. 2011. Pesticide exposure, safety issues, and risk assessment indicators. International Journal of Environmental Research and Public Health 8(5): 1402-1419.

Doretto, K.M., L.M. Peruchi and S. Rath. 2014. Sorption and desorption of sulfadimethoxine, sulfaquinoxaline and sulfamethazine antimicrobials in Brazilian soils. Science of the Total Environment 476: 406-414.

López-Garcí, B., A. Veyrat, E. Pérez-Payá, L. GonzálezCandelas and J. F. Marcos. 2003. Comparison of the activity of antifungal hexapeptides and the fungicides thiabendazole and imazalil against postharvest fungal pathogens. International journal of food microbiology 89(2): 163-170.

Muszynski, P., M.S. Brodowska, M. Pabich, M. Haliniarz and R. Czeczko. 2014. The sorption and degradation of sulfonylurea herbicides in soils. Przemysl Chemiczny 93(4): 531-535.

OECD. 2005. Guideline for the Testing of Chemicals. https://archive.epa.gov/scipoly/sap/meetings/web/pdf/ 106_adsorption_desorption_using.pdf [Accessed on: Jan 21, 2000

Onojake, M.C. and L.C. Osuji. 2012. Assessment of the physico-chemical properties of hydrocarbon contaminated soil. Arch. Appl. Sci. Resok 4(1): 48-58.

Rauf, N., S.S. Tahir, J.H. Kang and Y.S. Chang. 2012. Equilibrium, thermodynamics and kinetics studies for the removal of alpha and beta endosulfan by adsorption onto bentonite clay. Chemical engineering journal 192: 369-376.

Séïde, M., M. Marion, M.A. Mateescu and D.A. AverillBates. 2016. The fungicide thiabendazole causes apoptosis in rat hepatocytes. Toxicology in Vitro 32: 232-239.

Shariff, R.M. 2009. The study of adsorption and desorption of picloram on six agricultural soils. $J$ Univ Anbar Pure Sci 3(3): 13-24. 
Shariff, M.R. 2012. Effect of Co-pesticide on adsorptionDesorption Process on Agricultural Soils. International Journal of Engineering Research and Development 1(2): 55-69.
Suyal, A., S.S. Chauhan, A. Srivastava and P.C. Srivastava. 2013. Adsorption-desorption behaviour of chlorimuron-ethyl herbicide on homoionic clays. Eurasian Journal of Soil Science (EJSS) 2(1): 28-34. 